Original Article

\title{
GENOTYPE AND ABO BLOOD GROUP ASSOCIATION WITH PREVALENCE OF MALARIA AMONG PATIENTS IN UNIVERSITY OF NIGERIA MEDICAL CENTER: A CROSS-SECTIONAL EVALUATION
}

\section{ABDULMUMINU ISAH ${ }^{1}$, CHIBUEZE ANOSIKE ${ }^{1}$, AZUBUIKE AMOS EKWUOFU ${ }^{1}$, CHUKWUMA STEPHEN OGBODO ${ }^{2}$, CHARLES OBINNA EMEKA ${ }^{2}$, CHUKWUEMEKA SYLVESTER NWORU ${ }^{2}$}

${ }^{1}$ Department of Clinical Pharmacy and Pharmacy Management, University of Nigeria, Nsukka, Enugu State, Nigeria, ${ }^{2}$ Department of Pharmacology and Toxicology, University of Nigeria, Nsukka, Enugu State, Nigeria Email: abdulmuminu.isah@unn.edu.ng

Received: 09 Oct 2018 Revised and Accepted: 16 Apr 2019

ABSTRACT

Objective: The aim of this study was to evaluate the prevalence of malaria and its relationship with the ABO blood group and genotype at the University of Nigeria Medical Centre.

Methods: The study had a prospective cross-sectional design in which malaria status and blood groups and genotype were determined. All collected data were analysed using Statistical product and services Solution (V.21). Frequencies and percentages were used to describe the data while Chisquare and Pearson correlation were used to determine associations between malaria prevalence and patients' demographic and clinical characteristics. Statistical significance was considered for $p<0.05$.

Results: Three hundred and twenty-three (323) patients were tested for malaria, 245(75.9\%) of whom tested positive. The prevalence was highest for patient's aged 19-25 y (28.5\%). The difference was statistically significant for age: $\chi^{2}(5)=33.60, p=0.0005$. There were more blood group 0 (57.6\%) among the patients, while AA genotype was the majority (72.4\%). Those with blood group 0 had the highest prevalence of malaria (33.7\%) and it was statistically significant $\left(\chi^{2}(3)=72.10, p=0.0005\right)$ ). Correlation showed that the association between blood group and malaria prevalence was moderate $(\mathrm{R}=0.457)$. The AA genotype had more incidence of malaria $(54.5 \%)$, but the difference was not statistically significant.

Conclusion: The prevalence of malaria was high among the patients surveyed. Its association with the patients' ABO blood group was established to be statistically significant, with blood group 0 having the highest incidence. Although AA genotype was observed to have the highest cases of malaria, the relationship was found not to be significant.

Keywords: ABO Blood Group, Genotype, Malaria, Prevalence

(C) 2019 The Authors. Published by Innovare Academic Sciences Pvt Ltd. This is an open-access article under the CC BY license (http://creativecommons.org/licenses/by/4.0/) DOI: http://dx.doi.org/10.22159/ijpps.2019v11i6.30218

\section{INTRODUCTION}

Malaria remains an important global public health disease, despite many multinational efforts towards its treatment and eradication. The World Health Organization (WHO) reported that while 1.2 billion people were at high risk of being infected and developing the disease in 2015, an estimated 3.2 billion people in 95 countries and territories were at risk [1]. In the same year, World Malaria Report indicated that there were 214 million cases of the disease and 438 000 related deaths [1]. The prevalence increased to 216 million cases (in 91 countries) in 2016 [2]. Death from the disease remained around 445000 between 2015 and 2016. In all reports, Africa had the highest burden of the disease, with $90 \%$ of cases and $91 \%$ deaths being from the region in 2016. Two-thirds of all reported deaths were among children aged under 5 y [2]. To control and eliminate this top killer disease, an estimated US\$ 2.7 billion was spent in 2016, with governments of endemic countries contributing just about $31 \%$. Artemisinin-based combination therapies (ACTs) are currently the drugs of the first choice in the management of malaria, but concerns about the tastes of the oral preparation often affects compliance to prescribed regimens [3], apart from accessibility and affordability.

A good understanding of the aetiology of malaria will play a vital role in its elimination. It is the foundation of many researches on vaccinations against the disease [4-6]. Vector and host factors determine susceptibility to the disease. An example of vector factor is their feeding pattern which varies through the hours of a day, and even the seasons of a year. Some host factors (such as the region of residence and lifestyles like personal hygiene that expose individuals to the vector) and cooperation in control and eradication operations are modifiable [7, 8]. Hereditary and acquired factors are host-related factors that are not modifiable. Human blood groups and genotypes are two examples of hereditary and host-related factors that have been established to be related with susceptibility to some diseases [9]. The prevalence of malaria in the human population has been studied on the basis of these factors with no definite conclusion [10]. The co-adaptation of various human populations with widespread malaria parasites is clearly due to genetically-based alterations that confer protection against the disease $[11,12]$. This study sought to determine the prevalence of malaria and its association with genotypes and $\mathrm{ABO}$ blood groups among patients at the University of Nigeria Medical Centre.

\section{MATERIALS AND METHODS}

Design

This was a three-month prospective cross-sectional study that involved the collection of data from patients who were tested at the laboratory of the university medical center.

\section{Study site}

The University of Nigeria Medical Centre (UMC) Nsukka is a secondary level healthcare institution. It provides care primarily for staff (and their immediate families) and students of the university at its main campus. It is a 20-bed capacity hospital which provides outpatient/emergency services to patients and specialty care for some diseases. Referrals are made to the University of Nigeria Teaching Hospital Enugu where necessary.

\section{Ethical considerations}

Ethical clearance was obtained from the institutional review board of the institution before this study was conducted (Ref. No.: 
NHREC/05/01/2008B-FWA00002458-1RB00002323). All information collected from the patients were treated with confidentiality.

\section{Sampling procedure}

Only patients whose malaria tests were conducted in the laboratory of UMC were included in the study. Their genotype and ABO blood group determinations had to be determined at the UMC's laboratory as well. Patients (or guardians of minors) who refused to provide oral consent to participate in the study were not included.

\section{Data collection}

Qualified laboratory staff conducted the tests on eligible patients. Malaria test was conducted using the thick and thin film method as described by the WHO $[13,14]$. Genotype and ABO blood groups were determined using electrophoresis. Results of the tests were recorded in a data collection form designed for the purpose. The patients' demographic characteristics were also documented. The study was conducted from July to September 2017.

\section{Data analysis}

The collected data was first entered into Microsoft Excel (2016) and checked for correctness. It was then exported into Statistical Product and Services Solutions (Version 21) for Windows which was used for appropriate descriptive and inferential analyses. Frequencies and percentages were used to present the different laboratory results. The association between the malaria results and the patients' demographic characteristics was determined using Chisquare. Chi-square test and Pearson correlation were used to determine the relationship between the prevalence of malaria among the patients and their genotype and ABO blood groups. Statistical significance was considered for tests with $p$ values less than 0.05 .

\section{RESULTS}

Three hundred and twenty-three (323) patients were tested for malaria during the period of the study. Many of the patients were students (59.8\%), while the majority (95\%) were females. Other demographic characteristics are presented in table 1.

Table 1: Demographic characteristics of the patients

\begin{tabular}{|c|c|c|}
\hline & Frequency & Percentage \\
\hline \multicolumn{3}{|l|}{ Age (Years) } \\
\hline Less than 14 & 5 & 1.5 \\
\hline $15-18$ & 6 & 1.9 \\
\hline $19-25$ & 98 & 30.3 \\
\hline $26-30$ & 96 & 29.7 \\
\hline $31-35$ & 92 & 28.5 \\
\hline Greater than 35 & 26 & 8.0 \\
\hline Total & 323 & 100.0 \\
\hline \multicolumn{3}{|l|}{ Gender } \\
\hline Male & 16 & 5.0 \\
\hline Female & 307 & 95.0 \\
\hline Total & 323 & 100.0 \\
\hline \multicolumn{3}{|l|}{ University Status } \\
\hline Student & 193 & 59.8 \\
\hline Staff & 126 & 39.0 \\
\hline Others & 4 & 1.2 \\
\hline Total & 323 & 100.0 \\
\hline \multicolumn{3}{|l|}{ Pregnancy Status } \\
\hline Pregnant & 244 & 75.5 \\
\hline Non-pregnant & 79 & 24.5 \\
\hline Total & 323 & 100.0 \\
\hline
\end{tabular}

Of the 323 patients, $245(75.9 \%)$ tested positive for malaria. The prevalence was highest for patient's aged 19-25 y (28.5\%). When compared to the other age groups, the difference was statistically significant $\left(\chi^{2}(5)=33.60, p=0.00\right)$. There were more patients with blood group $0(57.6 \%)$ than those with other blood groups. Patients with AA genotype were the majority $(72.4 \%)$ in the population. Table 2 shows the clinical characteristics of the population while table 3 shows the relationship between the patients' independent characteristics and the malaria test results.

Table 2: Clinical characteristics of the patients

\begin{tabular}{|c|c|c|}
\hline & Frequency & Percentage \\
\hline \multicolumn{3}{|c|}{ ABO Blood Group } \\
\hline $\mathrm{A}$ & 69 & 21.4 \\
\hline B & 62 & 19.2 \\
\hline $\mathrm{AB}$ & 6 & 1.9 \\
\hline 0 & 186 & 57.6 \\
\hline Total & 323 & 100.0 \\
\hline \multicolumn{3}{|l|}{ Genotype } \\
\hline AA & 234 & 72.4 \\
\hline AS & 86 & 26.6 \\
\hline SS & 3 & .9 \\
\hline Total & 323 & 100.0 \\
\hline \multicolumn{3}{|c|}{ Malaria Test Result } \\
\hline Positive & 245 & 75.9 \\
\hline Negative & 78 & 24.1 \\
\hline Total & 323 & 100.0 \\
\hline
\end{tabular}


Table 3: Association between malaria status and demographic characteristics

\begin{tabular}{|c|c|c|c|}
\hline & \multicolumn{2}{|c|}{ Patient`s malaria test result } & \multirow[t]{2}{*}{ Total } \\
\hline & Positive & Negative & \\
\hline \multicolumn{4}{|c|}{ Age (Years) $\left[\chi^{2}(5)=33.6, p=0.00\right]$} \\
\hline Less than 14 & $4(1.2)$ & $1(0.3)$ & $5(1.5)$ \\
\hline $15-18$ & $5(1.5)$ & $1(0.3)$ & $6(1.9)$ \\
\hline $19-25$ & $92(28.5)$ & $6(1.9)$ & $98(30.3)$ \\
\hline $26-30$ & $67(20.7)$ & $29(9.0)$ & $96(29.7)$ \\
\hline $31-35$ & $55(17.0)$ & $37(11.5)$ & $92(28.5)$ \\
\hline Greater than 35 & $22(6.8)$ & $4(1.2)$ & $26(8.0)$ \\
\hline Total & $245(75.9)$ & $78(24.1)$ & $323(100.0)$ \\
\hline \multicolumn{4}{|c|}{ Gender $\left[\chi^{2}(1)=0.27, p=0.61\right]$} \\
\hline Male & $13(4.0)$ & $3(0.9)$ & $16(5.0)$ \\
\hline Female & $232(71.8)$ & $75(23.2)$ & $307(95.0)$ \\
\hline Total & $245(75.9)$ & $78(24.1)$ & $323(100.0)$ \\
\hline \multicolumn{4}{|c|}{ Status in the University $\left[\chi^{2}(2)=9.62, p=0.01\right]$} \\
\hline Student & $158(48.9)$ & $35(10.8)$ & 193(59.8) \\
\hline Staff & $84(26.0)$ & $42(13.0)$ & $126(39.0)$ \\
\hline Others & $3(0.9)$ & $1(0.3)$ & $4(1.2)$ \\
\hline Total & $245(75.9)$ & $78(24.1)$ & $323(100.0)$ \\
\hline \multicolumn{4}{|c|}{ Pregnancy Status $\left[\chi^{2}(1)=3.38, p=0.07\right]$} \\
\hline Pregnant & $179(55.4)$ & $65(20.1)$ & $244(75.5)$ \\
\hline Non-pregnant & $66(20.4)$ & $13(4.0)$ & $79(24.5)$ \\
\hline Total & $245(75.9)$ & $78(24.1)$ & $323(100.0)$ \\
\hline
\end{tabular}

Malaria prevalence was highest among patients with blood group 0 $(33.7 \%)$ compared to other groups. Chi-square test indicated that the difference was statistically significant $\left(\chi^{2}(3)=72.10, p=0.00\right)$ ). Pearson correlation showed that the association between blood group and malaria prevalence was moderate $(\mathrm{R}=0.457)$. Patients with AA genotype had more incidence of malaria $(54.5 \%)$. When compared to other genotypes, the difference was not statistically significant. Pearson correlation showed a weak relationship between malaria prevalence and genotype, as shown in table 4 . Table 5 shows the prevalence of malaria based on the blood group and genotype combination. The least susceptibility to malaria was in the combination of all genotypes and blood group A $(0.00)$.

Table 4: Association between the prevalence of malaria and patients' clinical characteristics

\begin{tabular}{|c|c|c|c|}
\hline & \multicolumn{2}{|c|}{ Patient`s malaria test result } & \multirow[t]{2}{*}{ Total } \\
\hline & Positive & Negative & \\
\hline \multicolumn{4}{|c|}{ Blood Group $\left[\chi^{2}(3)=72.10, p=0.00\right]$} \\
\hline \multicolumn{4}{|c|}{$\mathrm{R}=0.457$} \\
\hline A & $69(21.4)$ & $0(0.0)$ & $69(21.4)$ \\
\hline B & $62(19.2)$ & $0(0.0)$ & $62(19.2)$ \\
\hline $\mathrm{AB}$ & $5(1.5)$ & $1(0.3)$ & $6(1.9)$ \\
\hline 0 & $109(33.7)$ & $77(23.8)$ & $186(57.6)$ \\
\hline Total & $245(75.9)$ & $78(24.1)$ & $323(100.0)$ \\
\hline \multicolumn{4}{|c|}{ Genotype $\left[\chi^{2}(2)=0.39, p=0.82\right]$} \\
\hline \multicolumn{4}{|c|}{$\mathrm{R}=0.02$} \\
\hline A & $176(54.5)$ & $58(18.0)$ & $234(72.4)$ \\
\hline AS & $67(20.7)$ & $19(5.9)$ & $86(26.6)$ \\
\hline SS & $2(0.6)$ & $1(0.3)$ & $3(0.9)$ \\
\hline Total & $245(75.9)$ & $78(24.1)$ & $323(100.0)$ \\
\hline
\end{tabular}

Table 5: Malaria susceptibility based on blood group genotype combination

\begin{tabular}{|c|c|c|c|c|}
\hline \multirow[t]{2}{*}{ Blood group } & \multirow[t]{2}{*}{ Genotype } & \multicolumn{2}{|c|}{ Patient`s malaria test result } & \multirow[t]{2}{*}{ Total } \\
\hline & & Positive & Negative & \\
\hline \multirow[t]{3}{*}{ A } & $\mathrm{AA}$ & $50(72.5)$ & - & $50(72.5)$ \\
\hline & AS & $19(27.5)$ & - & $19(27.5)$ \\
\hline & Total & $69(100.0)$ & - & $69(100.0)$ \\
\hline \multirow[t]{3}{*}{ B } & $\mathrm{AA}$ & $47(75.8)$ & - & $47(75.8)$ \\
\hline & AS & $15(24.2)$ & - & $15(24.2)$ \\
\hline & Total & $62(100.0)$ & - & $62(100.0)$ \\
\hline \multirow[t]{3}{*}{$\mathrm{AB}$} & AA & $3(50.0)$ & $1(16.7)$ & $4(66.7)$ \\
\hline & AS & $2(33.3)$ & $0(0.0)$ & $2(33.3)$ \\
\hline & Total & $5(83.3)$ & $1(16.7)$ & $6(100.0)$ \\
\hline \multirow[t]{4}{*}{0} & $\mathrm{AA}$ & $76(40.9)$ & $57(30.6)$ & $133(71.5)$ \\
\hline & AS & $31(16.7)$ & $19(10.2)$ & $50(26.9)$ \\
\hline & SS & $2(1.1)$ & $1(0.5)$ & $3(1.6)$ \\
\hline & Total & $109(58.6)$ & $77(41.4)$ & $186(100.0)$ \\
\hline
\end{tabular}




\section{DISCUSSION}

This study was conducted in a university medical centre to determine the relationship between the prevalence of malaria and the patients' genotype and ABO blood groups. Most of the patients were middle-aged and almost all were females. Majority of the population were pregnant, and there were more students than staff among them. Laboratory results showed that more than half of the patients had blood group 0 . AA was the most observed genotype in the population. Majority of the patients who participated in the study tested positive for malaria. Patients' age and status in the university were the demographic characteristics that had a statistically significant relationship with their malaria test results. Blood groups showed a significant but moderate association with the prevalence of malaria. The prevalence of malaria among the patients had no significant association with their genotypes.

The demographic characteristics reported in this study compare reasonably with those of other studies conducted in similar settings. The reported middle age of most of the participants is understandable, as the majority of them were students. Most undergraduate students in Nigerian universities are about this age group, as shown in studies from different regions of the country [15-23]. The marital status of the participants in the study was not obtained. Thus, the high proportion of pregnant ones cannot be properly classified and attributed to any factor. It is worth noting that students in Nigerian universities have been reported to be highly sexually active [16], but with fair knowledge of emergency contraception $[16,20,21,23]$. Suffice it to mention however that in almost all endemic countries, malaria is more of a problem among under-five children [24]

The diagnosis of malaria is reliably done using rapid diagnostic tests in most cases settings at present, and it is as specific and sensitive as the peripheral blood smear test [25]. Many studies have reported the higher prevalence of malaria among blood group 0 patients compared to others. Zerihun et al., in Ethiopia, reported that most of their population that were confirmed to have malaria were of blood group 0 [26]. Their study established a significant relationship between the two variables, as in the present study. Another study in the same Ethiopia presented a similar result in terms of the higher incidence of malaria among blood group 0 [27]. A study in Southern Nigeria but among children reported a higher incidence of malaria among blood group 0 patients which was statistically significant [28]. Like the present study, a study that was conducted among students of a university in Nigeria reported a higher frequency for malaria among students with blood group 0 [29]. It was documented in that study that the association between malaria prevalence and blood group was significant among female students alone. A higher prevalence of malaria among group 0 patients was also reported in Ghana, but the result showed that there was no statistically significant difference [30]. A similar result was reported in a study among students of a university in Cameroun. In that study, blood group 0 had the higher incidence of malaria, but with no significan difference [31]. Nonetheless, blood group 0 has also being documented in other studies to confer protective advantage against severe malaria $[27,32]$.

The relationship between genotype and incidence of malaria has also been the subject of research by many authors. As in this study, a higher prevalence of malaria among patients with AA genotype was reported in Nigeria [28]. Unlike in this study, the observed difference was reported to be statistically significant. Another study in Nigeria presented a similar result [9]. While the study reported that the least susceptibility to malaria was in the combination of genotype AS and blood group 0 , the combination of all genotypes and blood group A was observed in the present study.

As studies present conflicting results, suffice it to repeat that the relationship between the prevalence of malaria and genetic factors will remain controversial. While some studies describe the prevalence of malaria in their population, some went deeper to classify the severity of the malaria or differences based on the causative organisms [33]. The present study did not classify the malaria and it is an apparent limitation. The study contributes to the body of knowledge about the prevalence of malaria and it is a fulcrum for further researches.

\section{CONCLUSION}

This study concludes that the prevalence of malaria was high among patients tested at the University of Nigeria Medical Centre. The association between the malaria prevalence among the patients and their ABO blood group was established to be statistically significant, with blood group 0 having the highest incidence. Although AA genotype was observed to have the highest cases of malaria among the patients, the relationship between malaria prevalence and genotype was found to be not significant.

\section{AUTHORS CONTRIBUTIONS}

Abdulmuminu Isah conceptualized the study, modalities of data collection and analysis. Chibueze Anosike drafted the manuscript, Chukwuma Ogbodo Stephen and Charles Obinna Emeka collected the data and participated in data analysis. Chukwuemeka Sylvester Nworu revised the manuscript. All authors approved the manuscript for publication.

\section{CONFLICTS OF INTERESTS}

\section{Declared none}

\section{REFERENCES}

1. World Health Organization. Malaria. World Health Organization 2016. Available from: http://www.who.int/gho/malaria/en/. [Last accessed 11 Jan 2018].

2. World Health Organization. Malaria. World Health Organization; 2017. Available from: http://www.who.int/ mediacentre/factsheets/fs094/en/. [Last accessed 11 January 2018].

3. Sonar YA, Bele MH, Sonar NH, Bagul VS, Shimpi PS. Taste abatement and characterization of dispersible tablets of artemether prepared by hot melt extrusion. Int J Appl Pharm 2017:9:28-33.

4. Arama C, Troye-Blomberg $M$. The path of malaria vaccine development: challenges and perspectives. J Intern Med 2014;275:456-66.

5. Hill AVS. Vaccines against malaria. Philos Trans R Soc Lond B Biol Sci 2011;366:2806-14.

6. Lorenz V, Karanis G, Karanis P. Malaria vaccine development and how external forces shape it: an overview. Int J Environ Res Public Health 2014;11:6791-807.

7. Ojiezeh TI, Ibeh NI, Opedun DO, Udoh SJ. Malaria endemicity among pregnant women in urban and semi-urban areas in Southwest, Nigeria. Am J Sci Res 2010;5:207-11.

8. William CM, Richard SD, Robert BG. Parasitology and vector biology. Second. Harcourt: Academic Press California; 2000.

9. Ito EE, Egwunyenga AO, Ake JEG. Prevalence of malaria and human blood factors among patients in Ethiope East, Delta State, Nigeria. Int J Med Biomed Res 2014;3:191-201.

10. Fortin A, Stevenson MM, Gros P. Susceptibility to malaria as a complex trait: big pressure from a tiny creature. Hum Mol Genet 2002;11:2469-78.

11. Driss A, Hibbert JM, Wilson NO, Iqbal SA, Adamkiewicz TV, Stiles JK. Genetic polymorphisms linked to susceptibility to malaria. Malar J 2011;10:271

12. Mendonc VRR De, Goncalves MS, Barral-netto M. The host genetic diversity in malaria infection. J Trop Med 2012;1-17. http://dx.doi.org/10.1155/2012/940616

13. World Health Organization. Malaria Parasite Counting. Geneva; 2016. Available from: http://www.wpro.who.int/mvp/ lab_quality/2096_oms_gmp_sop_09_rev1.pdf. [Last accessed 11 Jan 2018]

14. Bejon P, Andrews L, Hunt Cooke A, Sanderson F, Gilbert SC, Hill AVS. Thick blood film examination for Plasmodium falciparum malaria has reduced sensitivity and underestimates parasite density. Malar J 2006;5:104.

15. Olaitan L. Perception of university students on unwanted pregnancy in southwest Nigeria. Am J Soc Manag Sci 2010;1:196-200.

16. Ndifon W, Ogaji D, Etuk S. Sexuality, contraception and unintended pregnancy among female student nurses in Calabar, Nigeria. Benin J Postgrad Med 2006;8:12-21. 
17. Makanjuola AB, Daramola TO, Obembe AO. Psychoactive substance use among medical students in a Nigerian university. World Psychiatry 2007;6:112-4.

18. Oyetola EO, Oyewole T, Adedigba M, Aregbesola ST, Umezudike $\mathrm{K}$, Adewale A. Knowledge and awareness of medical doctors, medical students and nurses about dentistry in Nigeria. Pan Afr Med J 2016;23:1-12.

19. Chima Anyanwu F, Ter Goon D, Tugli A. Perception on the severity of unwanted pregnancy among university students. Pakistan J Med Sci 2013;29:923-8.

20. Ahmed ZD, Sule IB, Abolaji ML, Mohammed Y, Nguku P. Knowledge and utilization of contraceptive devices among unmarried undergraduate students of a tertiary institution in Kano State, Nigeria 2016. Pan Afr Med J 2017;26:103.

21. Adekanle DA, Adeniji AO. Emergency contraception: knowledge and practices of tertiary students in osun state, South Western Nigeria. Gynecol Obstet 2014;4:1.

22. Omobuwa 0, Alebiosu 0. Awareness of diabetes amongst undergraduates in a Nigerian University, South West Nigeria. Sahel Med J 2014;17:29.

23. Ojule J, Oriji V, George will K. Awareness and practice of emergency contraception among students of university of port harcourt, South-South Nigeria. Niger Heal J 2008;8:6-9.

24. Sarangi R, Pattnaik L, Satpathy SK, Sahu MC. Mortality pattern of under-five children-a hospital-based cross-sectional study in a tertiary care hospital of india. Asian J Pharm Clin Res 2017;10:82.

25. Gupta P, Gupta P, Rao S, Singh N, Kalita D. Comparison between microscopy and rapid diagnostic tests in diagnosis of malaria at a tertiary care medical institution in Uttarakhand (a 3-year study). Asian J Pharm Clin Res 2018;11:94.

26. Zerihun T, Degarege A, Erko B. Association of ABO blood group and Plasmodium falciparum malaria in. Asian Pac J Trop Biomed 2011;1:289-94.

27. Tekeste Z, Petros B. The ABO blood group and Plasmodium falciparum malaria in Awash, Metehara and Ziway areas, Ethiopia. Malar J 2010; 9:280.

28. Opara KN, Atting IA, Ukpong IG, Nwabueze AA, Inokon II. Susceptibility of genetic indices to falciparum malaria in infants and young children in Southern Nigeria. Pakistan J Biol Sci 2006;9:452-6.

29. Otajevwo FD. Prevalence of Malaria parasitaemia and its association with $\mathrm{ABO}$ blood grouping among students of igbinedion University Okada, Nigeria. Br J Med Med Res 2013;3:1164-77.

30. Muntaka S, Opoku Okrah C. The prevalence of malaria parasitaemia and predisposition of $\mathrm{ABO}$ blood groups to plasmodium falciparum malaria among blood donors at a ghanaian hospital. Au J T 2013;16:255-60.

31. Bamou R, Sevidzem SL. ABO/Rhesus blood group systems and malaria prevalence among students of the University of dschang, cameroon. Malaria World J 2016;7:5-8.

32. Rowe JA, Handel IG, Thera MA, Deans A, Lyke KE, Kone A, et al. Blood group 0 protects against severe Plasmodium falciparum malaria through the mechanism. PNAS 2007;104:44.

33. Migot Nabias F, Mombo LE, Luty AJF, Dubois B, Nabias R, Bisseye $\mathrm{C}$, et al. Human genetic factors related to susceptibility to mild malaria in Gabon. Genes Immun 2000;1:435-41. 